\title{
UNILATERAL VARIATION IN BRANCHING PATTERN OF THIRD PART OF LEFT AXILLARY ARTERY: A CASE REPORT
}

\section{B Muraleedhar*1, MS Danigond ${ }^{2}$.}

${ }^{*}$ HOD \& Associate professor Grameena Ayurvedic Medical College Terdal, Tq Jamkhandi Dist Baglkot, Karnataka, India.

${ }^{2}$ Chairman and Anatomy adviser dept of Anatomy SDMT Ayurvedic Medical College Terdal Tq Jamkhandi Dist Baglkot, Karnataka, India.

\section{ABSTRACT}

The Axillary artery is the continuation of the subclavian artery and is a major artery of the upper limb. During the routine dissection for undergraduate Ayurvedic medical students of SDM Trust's Ayurvedic Medical College, Terdal, Bagalkot, Karnataka, India, in the department of anatomy we come across a variation in branching pattern of third part of left axillary artery in male cadaver approximately 55 years of age. The first part and the second part of left axillary artery branches were found to be normal but third part of left axillary artery presenting only one common trunk. This common trunk running posteriorly and dividing into subscapular artery, Anterior circumflex Humeral Artery, Posterior circumflex Humeral Artery and profunda brachii artery.

KEY WORDS: Axillary Artery, Thoraco-Acromial Artery, Anterior And Posterior Circumflex Humeral Artery, Common Trunk, Subscapular Artery, Lateral Thorasic Artery.

Address for Correspondence: B Muraleedhar, MD (Ay) PhD, HOD \& Associate professor Grameena Ayurvedic Medical College Terdal, Tq Jamkhandi Dist Baglkot, Karnataka, India.

E-Mail: anatomymuralee@gmail.com

Quick Response code

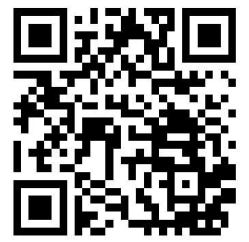

DOI: $10.16965 /$ ijar.2018.288 Journal Information

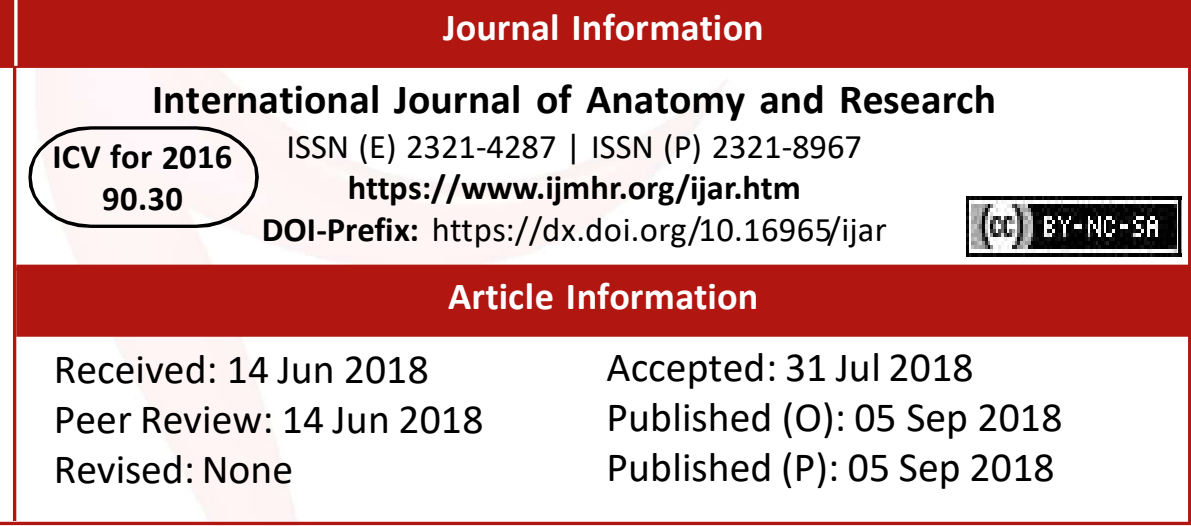

\section{INTRODUCTION}

The axillary artery is a large muscular blood vessel that travels through the axilla and conveys oxygenated blood to the lateral aspect of the thorax, axilla and upper limb. It is the continuation of the subclavian artery extending from the outer border of first rib to the lower border of Teres major muscle, there after it continues as brachial artery. The artery is closely related to the cords of the brachial plexus in axilla. Axillary artery is overlapped anteriorly by the pecrtoralis minor muscle and which divides the artery into three parts. First part of axillary artery lies between the lateral border of the first rib and the medial border of the pectoralis minor muscle and gives one branch named as the superior thoracic artery. Second part of the axillary artery lies under the pectoralis minor muscle. It gives two branches; the lateral thoracic artery and the thoracoacromial artery. The lateral thoracic artery continues downward along the lateral border of pectoralis minor. The thoracoacromial artery divides into 4 terminal branches namely acromial branch, clavicular branch, deltoid branch and pectoral branch. Third part of axillary artery lies between the lateral border of pectoralis minor and the lower border of the teres major muscle. It gives three 
branches; the subscapular artery, the anterior circumflex humeral artery and the posterior circumflex humeral artery [1].

Variation are the laws of nature, the proper observation is the surgeons feature. Anatomical variation of the branching pattern of axillary artery is very common. The knowledge of this variation is often useful during different surgical and interventional procedures. Variation of branching pattern of axillary artery is common during the dissection and $28 \%$ cases were reported by Samta et al in their study.

\section{CASE REPORT}

Fig. 1: Showing the variation in the branching pattern of third part of left axillary artery.

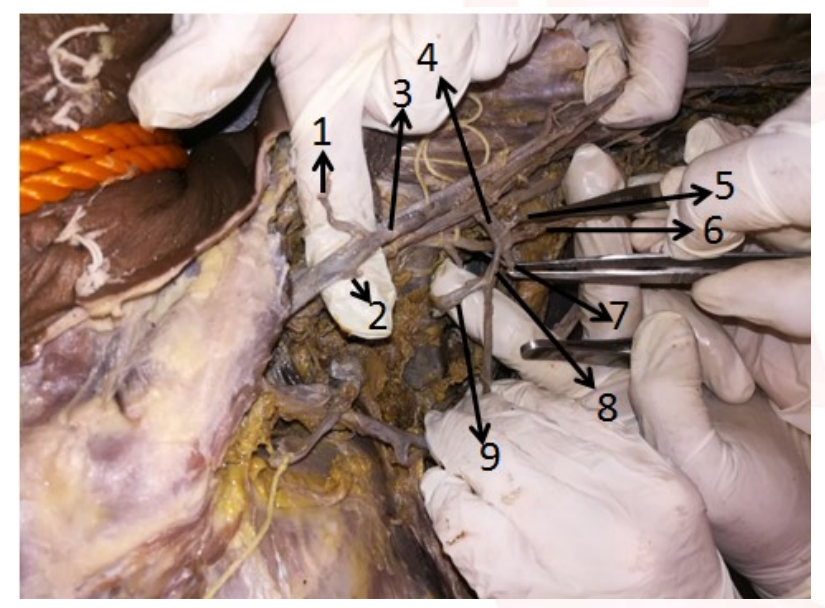

1. Thoraco-acromien artery, 2. Lateral thorasic artery, 3. Axillary artery, 4. Common trunk, 5. Posterior circumflex humeral artery, 6. Anterior circumflex humeral artery, 7. Profunda brachii artery 8 . Subscapular artery, 9. Circuflex subscapular artery

During the routine dissection for undergraduate ayurvedic medical students of SDM Trust's Ayurvedic Medical College, Terdal, Bagalkot, Karnataka, India, in the department of anatomy we come across a variation in branching pattern of left axillary artery in male cadaver approximately 55 years of age. Dissection of axillary region was conducted as per instructions of Cunningham manual. Anatomist and undergraduates found an interesting variation in the third part of left axillary artery, but the branches of right axillary artery were found to be normal. The first part and the second part of left axillary artery branches were found to be normal; Superior thoracic artery arose from first part, lateral thorasic artery and thoracoacromial artery arose from second part. But third part of left axillary artery presenting only one common trunk at the junction of medial and lateral root of median nerve instead of three branches. This common trunk running posteriorly and dividing into subscapular artery, Anterior circumflex Humeral Artery, Posterior circumflex Humeral Artery and profunda brachii artery. The profunda brachii artery of length $11 \mathrm{~cm}$ runs downward anterior to Teres major muscle and medial to radial nerve, while descending it gives many muscular branches that supply to triceps and profunda brachii artery runs near to lower triangular space where it is divided into two branches.

\section{DISCUSSION}

Anomalies in axillary artery with regard to origin, course and branching patterns are not frequent. During embryogenesis the lateral branch of seventh cervical inter segmental artery becomes enlarged to form the axial artery of upper limb which on further development becomes axillary, brachial, its bud gives rise to radial and ulnar arteries $[2,3]$.

Arey LB observed that, the unusual blood vessels may be due to 1.The choice of unusual paths in primitive vascular plexuses. 2 . The persistence of vessels which are normally obliterates. 3. The disappearance of vessels which are normally retained 4 . Incomplete development and fusion and absorption of the parts which are usually distinct [4].

Samta et al. reported that out of 50 cases, in 36 (68\%) cases having classic pattern of branching and $14(28 \%)$ cases having variation in branching pattern of axillary artery. Second part of axillary artery shows $12 \%$ and third part of axillary artery shows $16 \%$ Variation. In $30 \%$ of cases subscapular artery can arise from a common trunk with posterior circumflex humeral artery. Occasionally the subscapular, circumflex humeral and profunda brachii arteries arise in common trunk and also observed that in $4 \%$ cases posterior circumflex humeral artery is a large trunk arises with the subscapular artery [5]. This study shows that third part of axillary artery branching pattern variation rate is high. In our present case we observed variation in third part of axillay artery only.

T R Rao et al.reported that third part of the left axillary artery gave origin to subscapular, 
anterior and posterior circumflex humeral, profunda brachii, and ulnar collateral arteries from a common trunk [6]. In our present study we also observed that common trunk was originated from third part of left axillary artey but common trunk gave subscapular artery, anterior and posterior circumflex humeral artery and profunda brachii artery.

Samuel et al. reported a common trunk from the third part of the axillary artery giving rise to anterior circumflex humeral, posterior circumflex humeral, and subscapular arteries and which then descended into the arm to give radial collateral, middle collateral and continued as the superior ulnar collateral artery [7].

George et al. reported a case in which the axillary artery gave a large abnormal arterial trunk which in turn divided into a common circumflex humeral-subscapular trunk and profunda brachii artery [8].

Swamy Ravindra Shantakumar and K. G. Mohandas Rao were reported that the first part of axillary artery gave rise to superior thoracic artery as usual, but the second part gave a common trunk which divided into the lateral thoracic and subscapular arteries. The third part of the artery gave origin to anterior and posterior circumflex humeral arteries [9].

A K Manicka Vasuki et al reported that third part of axillary artery gave a common trunk which further divided in to subscapular artery anterioir circumplex humeral artery posterior circumflex artery and pronda branchii artery. This study correlates with our study but only difference is they found in right axillary artery but we found in left axillary artery [10].

\section{CONCLUSION}

Axillary artery variations are observed very commonly during dissection of axilla. The proper knowledge of Axillary artery variation is most important for surgeons, Radiologists, Anesthetists, and Orthopedicians for the betterment of mankind.

\section{Conflicts of Interests: None}

\section{REFERENCES}

[1]. Susan standring. Pectoral girdle, Shoulder region and axilla in the anatomical basis of clinical practice, Gray's Anatomy.40th ed.London: Churchill Livingstone 2008.p.817.

[2]. Tan C B, Tan C K. An unusual course and relations of the human axillary artery. Singapore Med J 1994; 35: 263-264.

[3]. Jurjus AR, Correa-De-Aruaujo R, Bohn RC. Bilateral double axillary artery: embryological basis and clinical implications. Clin Anat 1999;12:135-140.

[4]. Arey IB. Developmental Anatomy. $6^{\text {th }}$ ed. Philadelphia, W.B.Saunders. 1957;375-77.

[5]. S. Gaur, S. K. Katariya, H. Vaishnani et al., A cadaveric study of branching pattern of the axillary artery," International Journal of Biological and Medical Research, 2012;3(1):1388-1391.

[6]. T. R. Rao, P. Shetty, and R. Suresh. Abnormal branching pattern of the axillary artery and its clinical significance. International Journal of Morphology, 2008;26(2):389-392.

[7]. V. P. Samuel, V. R. Vollala, S. Nayak, M. Rao, S. R. Bolla, and N. Pammidi. A rare variation in the branching pattern of the axillary artery," Indian Journal of Plastic Surgery, 2006;39(2):222-223.

[8]. B. M. George, S. Nayak, and P. Kumar. Clinically significant neurovascular variations in the axilla and the arm-a case report. Neuroanatomy, 2007;6:36-38.

[9]. Swamy Ravindra Shantakumar and K. G. Mohandas Rao. Variant Branching Pattern of Axillary Artery: A Case Report," Case Reports in Vascular Medicine 2012; Article ID 976968.

[10]. A.K.Manicka Vasuki, M.Nirmala Devi, K.Kalyana Sundaram, Deborah Joy Hebzibah, T.K.Aleyemma Fenn, M.Jamuna. Unilateral Variation In The Branching Pattern Of Right Axillary Artery: A Case Report. Int J Anat Res 2015;3(3):1312- 1315. DOI: 10.16965/ ijar.2015.218.
How to cite this article:
B Muraleedhar, M S Danigond. UNILATERAL VARIATION IN BRANCHING PATTERN OF THIRD PART OF LEFT AXILLARY ARTERY: A CASE REPORT. Int J Anat Res 2018;6(3.3):5602-5604. DOI: 10.16965/ijar.2018.288 